\title{
Thrombospondin-1 regulates the normal prostate in vivo through angiogenesis and TGF- $\beta$ activation
}

\author{
Philip P Fitchev ${ }^{1}$, Susan M Wcislak ${ }^{1}$, Chung Lee ${ }^{2,3}$, Anders Bergh ${ }^{4}$, Charles B Brendler ${ }^{1}$, Veronica M Stellmach ${ }^{5}$, \\ Susan E Crawford ${ }^{1}$, Constantine D Mavroudis ${ }^{5}$, Mona L Cornwell ${ }^{1}$ and Jennifer A Doll ${ }^{1}$
}

Castration experiments in rodents show that the stromal vasculature is critical to the androgen-mediated prostate growth regulation. However, the role of angiogenesis inhibitors, such as thrombospondin-1 (TSP-1), in this process is unclear. TSP-1 is a multifunctional glycoprotein that can function as a potent angiogenesis inhibitor and an in vivo activator of latent transforming growth factor- $\beta$ (TGF- $\beta$ ) in some tissues. On the basis of these observations, we hypothesized that TSP-1 regulated androgen withdrawal-induced prostate regression and that this process was mediated not only through antiangiogenic activity but also through TGF- $\beta$ activation. To test this, we evaluated angiogenic activity in human prostate epithelial and stromal cells treated with androgens and hypoxia in vitro. TSP-1 knockout mice were characterized to investigate the in vivo functions of TSP-1. In vitro, we found that androgens and hypoxia differentially regulated TSP-1 and angiogenic activity. Androgens stimulated normal epithelial cell, but inhibited normal stromal cell, angiogenic activity. Conversely, hypoxia stimulated stromal while inhibiting epithelial activity. Thus, in vivo, net angiogenic activity must reflect cellular interactions. And, we found that media conditioned by epithelial cells grown under normoxic conditions stimulated stromal cell angiogenic activity, and if epithelial cells were grown under hypoxic conditions, stromal activity was further increased. TSP-1 levels, however, were unchanged. In vivo, TSP-1 loss in a mouse model led to prostate epithelial hyperplasia by 3 months of age with only a modest stromal effect. Androgens suppressed TSP-1 as expression increased after castration both in normal mouse prostate and in human prostate cancer tissues. In addition, TSP-1 expression corresponded to increased TGF- $\beta$ activation in mouse tissues, specifically in the stromal compartment. These data show a critical role for TSP-1 in prostate epithelial and stromal growth regulation through angiogenic inhibition and activation of latent TGF- $\beta$. Therefore, loss of TSP- 1 during tumorigenesis would eliminate two barriers to cancer progression.

Laboratory Investigation (2010) 90, 1078-1090; doi:10.1038/labinvest.2010.90; published online 10 May 2010

KEYWORDS: angiogenesis; cancer; prostate; thrombospondin-1; transforming growth factor- $\beta$; vascular endothelial growth factor

Androgens stimulate prostate growth during development, and maintain the gland in adulthood. This modulation of prostate growth by androgens is mediated in part through regulation of angiogenesis. In the normal adult prostate, blood vessels are maintained in a quiescent state in the stroma by a predominance of angiogenic inhibitors over inducers in the tissue milieu. Induction of angiogenesis is necessary for tumor progression, and supporting this, many studies have shown that increased microvascular density (MVD) has prognostic value in prostate cancer (PCa) patients. ${ }^{1-4}$ We have previously shown that, compared to normal prostate epithelial cells (PrECs), the balance of angiogenic mediators is altered in PCa cells; ${ }^{5,6}$ however, the stromal contribution to angiogenesis has not been well studied.

In the normal rodent prostate, androgen withdrawal induces endothelial cell apoptosis and vascular regression before epithelial cell apoptosis. ${ }^{7-13}$ The initial vascular regression is likely due to a sharp decrease in levels of the angiogenesis inducer, vascular endothelial growth factor (VEGF). ${ }^{14}$ In the rat prostate, the microvascular endothelial cells do not express the androgen receptor. ${ }^{15,16}$ Thus, rather than a direct effect on the endothelial cells, the effects of androgen withdrawal are likely mediated through the

\footnotetext{
${ }^{1}$ Department of Surgery, NorthShore University HealthSystem Research Institute, Evanston, IL, USA; ${ }^{2}$ Department of Urology, Northwestern University Feinberg School of Medicine, Chicago, IL, USA; ${ }^{3}$ Robert H. Lurie Comprehensive Cancer Center, Northwestern University Feinberg School of Medicine, Chicago, IL, USA; ${ }^{4}$ Department of Pathology, Umea University, Umea, Sweden and ${ }^{5}$ Department of Pathology, Northwestern University Feinberg School of Medicine, Chicago, IL, USA Correspondence: Dr JA Doll, PhD, Department of Surgery, NorthShore University HealthSystem Research Institute, 1001 University Place, Evanston, IL 60201, USA. E-mail: jdoll@northshore.org 
androgen receptor-positive epithelial and stromal cells. Supporting this, androgen treatment does stimulate VEGF expression in normal PrECs and in androgen-sensitive PCa cells. ${ }^{12,17}$ However, in the rat model, VEGF levels rebound to baseline by 3 days after castration. ${ }^{18-20}$ This rebound is likely due to the tissue hypoxia resulting from the vascular regression. ${ }^{18-20}$ However, despite the hypoxia-induced increase in VEGF, vascular regression continues. These observations indicate that other angiogenic mediators must participate in suppressing the vasculature. We have previously shown increased expression of the angiogenesis inhibitor, pigment epithelium-derived factor (PEDF), after androgen withdrawal in both rodent and human PCa tissues, ${ }^{6}$ thus, identifying one inhibitor in the continued regression. We have also observed that another angiogenesis inhibitor, thrombospondin-1 (TSP-1), is strongly expressed in normal prostate tissues, and this expression is downregulated in human PCa tissues. ${ }^{5}$ In vitro, the TSP-1 secreted by normal PrECs functions as an angiogenesis inhibitor. ${ }^{5}$ Colombel et $a l^{21}$ have observed increased TSP-1 expression after castration in a rat model, and in $\mathrm{PCa}$ patients receiving androgen deprivation therapy (ADT), tissue levels of TSP-1 increased whereas VEGF decreased compared to those patients who had no hormone therapy. ${ }^{4}$ These observations suggest that TSP- 1 could be a second angiogenesis inhibitor functioning in the continued vascular regression. However, the direct effect of androgens and hypoxia on TSP-1 regulation and angiogenic activity in normal prostate epithelial and stromal cells has not been investigated.

TSP-1 is a multifunctional glycoprotein secreted by a variety of cell types, including endothelial and epithelial cells, fibroblasts and smooth muscle cells, ${ }^{22}$ so its inhibitory effects on the prostate are unlikely to be through angiogenic regulation alone. TSP-1 activates latent transforming growth factor- $\beta$ (TGF- $\beta$ ) in vivo in some tissues, ${ }^{23-25}$ and TGF- $\beta$ inhibits proliferation and stimulates apoptosis of normal prostatic epithelial cells and functions in stromal differentiation. In the early stages of PCa, TGF- $\beta$ inhibits tumor progression. ${ }^{26}$ Therefore, TSP- 1 activation of TGF- $\beta$ could be critical in regulating prostate growth. Similar to TSP-1, TGF- $\beta$ levels increase in the human prostate after castration, ${ }^{27}$ suggesting that TGF- $\beta$ may function in the regression process. Interestingly, in normal rat prostatic epithelial cells, either $1 \alpha, 25$-dihydroxy vitamin D3 or retinoic acid increased both TSP- 1 and TGF- $\beta$ expression, and the increase in TSP-1 could be inhibited by anti-TGF- $\beta$ antibodies. ${ }^{28}$ These data suggest coordinated regulation between these molecules in the prostate.

On the basis of the above observations, we hypothesized that the angiogenesis inhibitor TSP-1 has a major role in prostate growth and homeostasis and has a critical role in the androgen withdrawal response. Moreover, function of TSP-1 in both epithelial and stromal cells was mediated not only through its antiangiogenic activity but also, in part, through its activation of latent TGF- $\beta$. To test this hypothesis, we evaluated the in vitro angiogenic activity of normal PrECs and cancer epithelial cells as well as normal stromal cells to the two stimuli important in the castration responseandrogen and hypoxia. To evaluate the function of TSP-1 in the prostate in vivo, we used a surgical castration model and characterized the prostate phenotype of TSP-1 knockout (KO) mice.

\section{MATERIALS AND METHODS \\ Cell Culture}

Human normal prostate epithelial and stromal cell strains and dermal microvascular endothelial cells were purchased from Lonza (Walkersville, MD, USA) and maintained per the manufacturer's instructions. PCa cell lines DU145, LNCaP and PC-3 were obtained from the American Type Culture Collection and maintained in Dulbecco's modified Eagle's medium plus 10\% fetal bovine serum and antibiotics. Short-term cultures of normal prostate stromal cells (PrSCs) were established as described. ${ }^{5,6}$ Androgen treatments were performed using the testosterone derivative, dihydrotestosterone (DHT) at $0-10^{-7} \mathrm{M}$ as previously described. ${ }^{6}$ For hypoxia experiments, normoxia was standard culture conditions $\left(20 \% \mathrm{O}_{2}\right)$, and hypoxia was induced by growth at $0.5 \% \mathrm{O}_{2}$ in a hypoxia chamber or by treatment with $100 \mu \mathrm{M}$ cobalt chloride $\left(\mathrm{CoCl}_{2}\right)$, a chemical mimic of hypoxia. ${ }^{29}$ TGF- $\beta$ neutralizing antibody (Genzyme) was used at $10 \mu \mathrm{g} / \mathrm{ml}$. Serum-free conditioned media was collected as described. $^{5,6}$ Results were analyzed from at least two independent experiments on each cell type with consistent results.

\section{Angiogenesis Assay}

Angiogenic activity in the conditioned media was evaluated using the microvascular endothelial cell migration assay as previously described. ${ }^{5}$ Serum-free medium, containing $0.1 \%$ bovine serum albumin, served as the control for background migration, and human VEGF $(250-500 \mathrm{pg} / \mathrm{ml})$ or basic fibroblast growth factor $(15 \mathrm{ng} / \mathrm{ml})$ (R\&D Systems, Minneapolis, MN, USA) served as the positive control (250-500 pg/ml). Neutralizing TSP-1 antibody (clone A4.1; Thermo Fisher, Fremont, CA, USA) was used at $40 \mu \mathrm{g} / \mathrm{ml}$ as previously described. ${ }^{5}$ Controls for the neutralizing activity of this antibody were included in the assays (Supplementary Figure 1a), and we have previously shown the specificity of this antibody to TSP-1. ${ }^{30,31} \mathrm{CoCl}_{2}(0-100 \mu \mathrm{M})$ and DHT $\left(0-10^{-7} \mathrm{M}\right)$ were also tested alone as controls, and no change in activity from background levels was observed with either substance (Supplementary Figure 1b,c). All samples were tested in quadruplicate, and results were reported as mean percent of maximal migration toward the positive control \pm standard error (s.e.).

\section{Protein Analysis}

TSP-1 and PEDF levels in serum-free conditioned media were analyzed by western blot as previously described. ${ }^{5,6}$ 
Equal protein loading was verified by Coomassie staining of identically loaded gels. Purified protein was included on gels (20-30 ng per lane) as a positive control, and Bio-Rad prestained molecular weight markers (Hercules, CA) were included as size standards. Relative band intensities were determined using densitometry and values normalized to Coomassie staining intensity. VEGF protein levels in conditioned media were quantified by enzyme-linked immunosorbent assay (ELISA; R\&D Systems) per manufacturer's instructions. Data are presented as the mean \pm standard deviation (s.d.) of duplicate wells.

\section{Animal Model}

The construction of the TSP-1 KO mouse has been described. ${ }^{32}$ Prostate tissues from TSP-1 KO and wild-type $\mathrm{C} 57 \mathrm{Bl} / 6$ control mice, the background strain of the TSP-1 KO model, were harvested from mice at 1-25 months of age at seven time points $(1,3,6,9,12,18$ and 25 months). At least five mice per age group were used for comparison between genotypes. Castration was performed on wild-type and TSP-1 $\mathrm{KO}$ mice at 5-6 months of age, and prostate tissues were harvested at days 1-21 after castration (time points 1, 3, 5, 7, 14 and 21 days; $n=5$ per group). All animals used in these studies were housed in accordance with guidelines from the American Association for Laboratory Animal Care, and all research protocols were approved by the Institutional Animal Care and Use Committee.

\section{Human Prostate Tissues}

Human prostate biopsy specimens were taken before and 3-7 days after surgical castration from PCa patients $(n=8)$ at Umea University (Umea, Sweden). Human tissue collection was approved by internal review board committees and all guidelines for patient consent were followed.

\section{Tissue Analysis}

Tissues were formalin-fixed, paraffin-embedded and sectioned for staining. A hematoxylin and eosin (H\&E) stain was performed for tissue characterization, and an avidin/ biotin/peroxidase protocol was used for immunostaining. Antibodies were used as followed: anti-TSP-1 (Thermo Fisher), anti-total and anti-active TGF- $\beta$ (R\&D Systems), proliferating cell nuclear antigen (PCNA) as a measure of cell proliferation, and anti-Factor VIII-related antigen to determine MVD as a measure of angiogenesis (Dako, Carpinteria, CA). Slides with omission of the primary antibody served as the negative control. Cell types were identified by morphology. TGF- $\beta$ staining intensity was graded by assigning a grade of 1,2 or 3 to individual glands with staining positivity as $<35 \%, 36-75 \%$ and $>75 \%$ epithelial cells positive, respectively, and a score assigned by averaging gland intensity. A minimum of 25 glands per mouse were counted. PCNA and MVD were quantified as described. ${ }^{5,6}$ TSP-1 staining was quantified as previously described. ${ }^{5}$

\section{Statistical Analysis}

Statistical significance of the data was determined using Student's $t$-tests with $P$-values $\leq 0.05$ considered significant.

\section{RESULTS \\ DHT Increases Angiogenic Activity in Both Normal Prostate Epithelial and PCa Cells}

We have observed that TSP-1 localizes to both the stromal and epithelial cells in human prostate tissue and that this TSP-1 expression is decreased in human PCa patient tissues. ${ }^{5}$ We have also shown that normal PrECs secrete TSP-1 in vitro whereas the androgen-sensitive $\mathrm{LNCaP}$ and androgeninsensitive PC-3 PCa cell lines do not. ${ }^{5}$ After castration, the drop in androgens initiates vascular regression that in turn induces tissue hypoxia. Therefore, we investigated the effects of both androgen and hypoxia on angiogenic activity and TSP-1 expression. We treated cells with DHT, a potent testosterone derivative, or incubated them in hypoxic conditions and tested angiogenic activity in the serum-free conditioned media using a microvascular endothelial cell migration assay. VEGF and TSP-1 levels were measured by ELISA and western blot analysis, respectively. In control experiments, DHT alone did not affect the migration of endothelial cells, indicating that DHT does not directly elicit angiogenesis (Supplementary Figure 1b). However, DHT treatment did significantly increase angiogenic activity in PrECs at both the $10^{-12}$ and $10^{-10} \mathrm{M}$ DHT doses, low and high proliferative doses, respectively, by more than $20 \%$ over untreated cells (Figure 1a; $P<0.05$ ). With the $10^{-7} \mathrm{M}$ DHT treatment, a growth static dose, there was no change in angiogenic activity compared to untreated cells (Figure 1a). Similar results were obtained with androgen-sensitive LNCaP PCa cells. DHT treatment increased angiogenic activity by 16 and $25 \%$ at the $10^{-12}$ and $10^{-10} \mathrm{M}$ doses, respectively, and again with no change at the $10^{-7} \mathrm{M}$ treatment, compared to untreated cells (Figure 1b; $P<0.05$ ). Consistent with published studies, ${ }^{7,8,11-13,18}$ with the $10^{-10}$ and $10^{-7} \mathrm{M}$ DHT treatments, VEGF levels were increased in both normal PrECs by 40 and $82 \%$, respectively, and in LNCaP cells, by 47 and $29 \%$, respectively (Figure $1 \mathrm{c}$ and d; $P<0.05$ ). TSP-1 secretion was not significantly altered by DHT treatment in PrECs (Figure 1e). In our previous studies, the angiogenesis inhibitor PEDF was also not altered by DHT treatment. ${ }^{6}$ Thus, in normal PrECs and androgen-sensitive PCa cells, androgens stimulate angiogenic activity due to increased VEGF levels.

\section{Unlike Normal PrECs, Hypoxia Increases Angiogenic Activity in PCa Cells}

In most cancer cells, hypoxia increases VEGF and angiogenic activity. In LNCaP cells, hypoxia stimulated angiogenic activity by almost $50 \%$ (Figure 2a; $P<0.05$ ), and this increase in activity corresponded to a sixfold increase in VEGF (Figure 2b; $P<0.05$ ). Because LNCaP cells do not secrete either TSP-1 or PEDF, ${ }^{5,6}$ the high level of VEGF may be responsible for the angiogenic induction. Similar results were obtained with the 

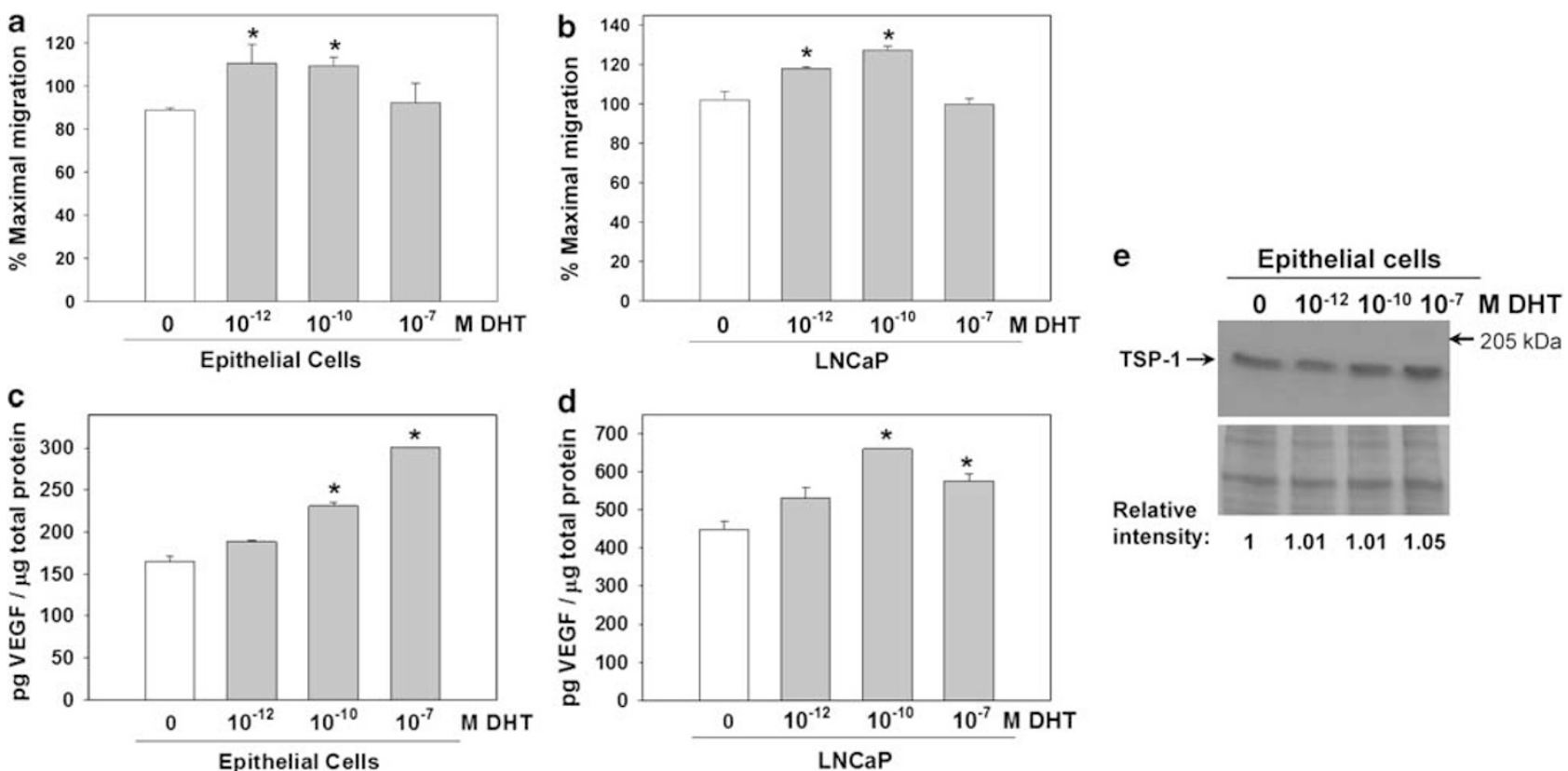

Figure 1 Androgens induce angiogenic activity in prostate epithelial cells. Serum-free conditioned media were collected from normal prostate epithelial cells (PrECs) and from androgen-sensitive LNCaP PCa cells treated with DHT (0-10 $\left.{ }^{-7} \mathrm{M}\right)$. (a and b) Angiogenic activity was assessed in PrECs and LNCaP conditioned media $(20 \mu \mathrm{g} / \mathrm{ml})$ using a microvascular endothelial cell migration assay, and data are presented as the mean \pm s.e. of the percent maximum migration toward the positive control. (c and d) VEGF levels were measured in conditioned media by ELISA. Data are presented as mean \pm s.d. of two replicates. (e) TSP-1 expression was evaluated by western blot. The lower panel is an identically loaded gel to show equal protein loading between lanes. Protein levels relative to untreated $(0 \mathrm{DHT})$ were determined by densitometry. Protein size standard is indicated. ${ }^{*}$ Significantly different compared to the untreated cells within each experiment, $P<0.05$.

androgen-insensitive PC-3 PCa cell line whereby hypoxia increased angiogenic activity by almost $50 \%$ and was associated with a threefold increase in VEGF (Figure 2a and b; $P<0.05)$. Although PC-3 cells do not secrete TSP- $1,{ }^{5}$ they do secrete PEDF, which we have previously reported to be downregulated by hypoxia; ${ }^{6}$ thus, net angiogenic activity can be augmented by only a modest increase in VEGF.

In striking contrast to the cancer cells, hypoxia suppressed angiogenic activity secreted by normal PrECs by $45 \%$ compared to untreated (Figure $2 \mathrm{c} ; P<0.05$ ). Although VEGF levels were increased by $41 \%$ with hypoxia compared to untreated cells, TSP-1 was inhibited by hypoxia or $\mathrm{CoCl}_{2}$, a chemical mimetic of hypoxia, by more than $30 \%$ (Figure $2 \mathrm{~d}$ and e). Because we previously observed hypoxic induction of PEDF in these cells, ${ }^{6}$ it appears that the PEDF is key to maintaining the antiangiogenic activity in normal epithelial cells under hypoxic stimuli.

\section{Stromal Cell Response to DHT and Hypoxia Opposes That of Normal Epithelial Cells}

As TSP-1 localizes to the prostate stroma in vivo and normal PrSCs secrete TSP-1 in vitro, ${ }^{5}$ we tested the response of PrSCs to DHT and hypoxia as above. Surprisingly, in contrast to normal epithelial cells, angiogenesis was significantly decreased in PrSCs with DHT treatment by over $55 \%$ at all doses tested $\left(10^{-12}\right.$ to $\left.10^{-7} \mathrm{M}\right)$ compared to untreated cells (Figure 3a; $P<0.05$ ). However, VEGF was increased threefold at $10^{-12} \mathrm{M}$ DHT, though higher concentrations had no effect compared to untreated cells (Figure $3 \mathrm{~b} ; P<0.05$ ). TSP-1 secretion was decreased in a dose-dependent manner by DHT treatment by $25-34 \%$ (Figure 3c). Our previous experiments showed that DHT treatment also decreases PEDF in a dosedependent manner. ${ }^{6}$ Thus, at the $10^{-12} \mathrm{M}$ DHT concentration, the TSP-1 and PEDF levels are likely still sufficient to inhibit angiogenesis even with the increased VEGF. The inhibition at the higher doses with decreased TSP-1 and PEDF suggests that additional molecules are involved.

In contrast to DHT treatment, hypoxia significantly increased angiogenic activity by $41 \%$ in PrSCs (Figure 3d; $P<0.05)$. Consistent with published studies, ${ }^{33}$ hypoxia treatment increased PrSC VEGF secretion by $77 \%$ compared to untreated cells (Figure 3e; $P<0.05$ ). However, TSP-1 secretion levels were not altered (Figure 3f). Our previous experiments showed suppression of PEDF by hypoxia in these cells, ${ }^{6}$ so this taken with the increase in VEGF may explain the net increase in angiogenic activity.

\section{TSP-1 Contribution to Angiogenic Activity in Stromal Cells}

To verify that the TSP-1 secreted by PrSCs under DHT or hypoxia treatment had antiangiogenic function, we tested activity in the presence of neutralizing TSP-1 antibody. Consistent with our previous results, ${ }^{5}$ neutralizing TSP-1 antibody significantly increased secreted angiogenic activity 

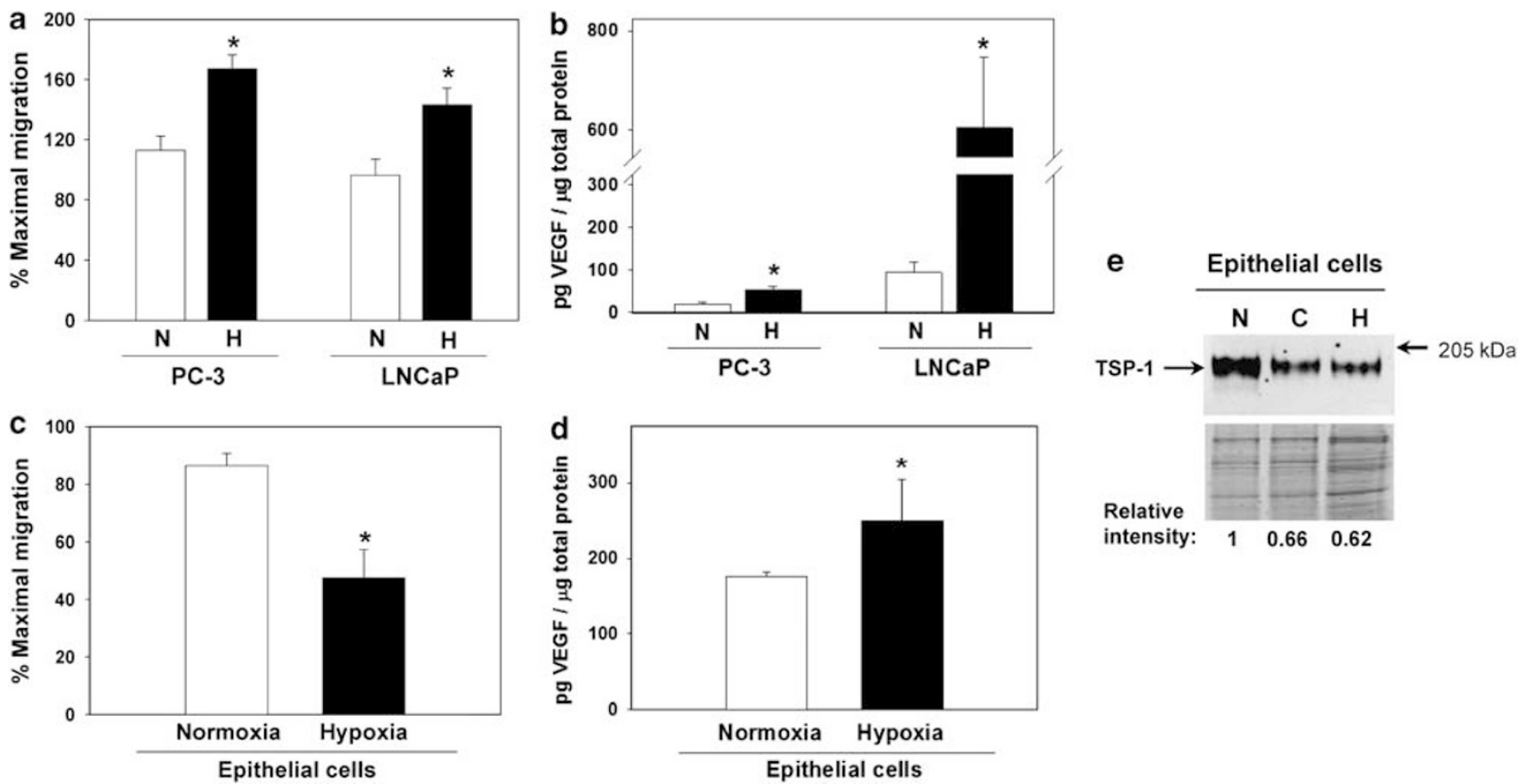

Relative

Figure 2 Hypoxia inhibits angiogenesis and TSP-1 expression in normal prostate epithelial cells whereas angiogenesis is induced in PCa cells. Normal prostate epithelial cells (PrECs) and androgen-sensitive LNCaP and androgen-insensitive PC-3 PCa cells grown under standard conditions (normoxia, N) or hypoxia-treated conditions $\left(50 \mu \mathrm{M} \mathrm{CoCl}_{2}(\mathrm{C})\right.$ or in a hypoxia chamber $\left.(\mathrm{H}), 0.5 \% \mathrm{O}_{2}\right)$ and serum-free conditioned media were collected. $(\mathbf{a})$ Angiogenic activity of PC-3 and LNCaP conditioned media $(20 \mu \mathrm{g} / \mathrm{ml})$ was assessed using a microvascular endothelial cell migration assay. Data are presented as mean \pm s.e. of the percent maximum migration toward the positive control. (b) VEGF levels were assayed by ELISA, and data are presented as mean \pm s.d. (c) Angiogenic activity (d) and VEGF levels were evaluated in PrECs as above. (e) TSP-1 expression was evaluated by western blot analysis. The lower panel is an

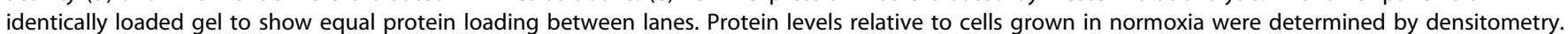
Protein size standard is indicated. ${ }^{*}$ Significantly different compared to cells grown under normoxic conditions, $P<0.05$.

in untreated cells by 55\% (Figure $3 \mathrm{~g} ; \mathrm{P}<0.05$ ). In this assay, we used $\mathrm{CoCl}_{2}(100 \mu \mathrm{M})$ to mimic hypoxia, and in control experiments, $\mathrm{CoCl}_{2}$ alone showed no affect on angiogenic activity (Supplementary Figure 1c). In normal stromal cells, $\mathrm{CoCl}_{2}$ treatment stimulated angio-inductive activity by $40 \%$ compared to untreated cells (Figure $3 g ; P<0.05$ ). Addition of neutralizing TSP-1 antibody further increased this activity by 42 and $98 \%$ compared to $\mathrm{CoCl}_{2}$-treated and $\mathrm{CoCl}_{2}$-untreated cells, respectively (Figure 3g; $P<0.05$ ). Conversely, DHT treatment $\left(10^{-7} \mathrm{M}\right)$ inhibited activity by $28 \%$, but addition of neutralizing TSP-1 antibody relieved this inhibition, increasing activity by 90 and 36\% compared to DHT-treated and DHT-untreated cells, respectively (Figure 3g; $\mathrm{P}<0.05$ ). When PrSCs were subjected to both DHT and $\mathrm{CoCl}_{2}$ treatment, the net response was angio-inductive but was not significantly different from $\mathrm{CoCl}_{2}$ alone (Figure $3 \mathrm{~g}$ ). These data confirm that stromal-derived TSP-1 retains potent antiangiogenic activity and show that in the setting of androgen withdrawal-induced hypoxia, isolated stromal and epithelial cells have opposing angiogenic activity.

\section{Epithelial Secretions Stimulate Stromal Angiogenic Response}

As the blood vessels reside within the prostate stroma, it is likely that epithelial cell secretions modify the stromal angiogenic response. To investigate this, we incubated PrSCs in media conditioned by PrECs grown under normal or hypoxic conditions. Because PrSCs are grown in a different culture media than PrECs, we tested the effects of the PrEC media alone on PrSCs as a control, and we did observe an increase in angiogenic activity of PrSCs $(P<0.05$; Figure $4 \mathrm{a})$. However, incubation of PrSCs in media conditioned by PrECs significantly increased activity by $25 \%$ over that of the epithelial media alone $(P<0.03$; Figure $4 a)$. Moreover, incubation of PrSCs in media conditioned by PrECs grown in hypoxic conditions further increased activity by an additional 35\% $(P<0.003$; Figure 4a). Consistent with the results above, hypoxia increased VEGF levels in PrECs (Figure 4b). Although incubation of PrSCs in epithelial media alone did not alter VEGF levels, incubation in media conditioned by PrECs from both normoxic and hypoxic conditions significantly increased VEGF levels by twofold compared to the media control $(P<0.005$; Figure $4 \mathrm{~b})$. However, VEGF levels were not different between PrSCs treated with PrEC normoxia or hypoxia conditioned media (Figure $4 \mathrm{~b}$ ). The increase in angiogenic activity was independent of TSP-1 or PEDF because their expression levels were not changed (Figure 4c). These data show that epithelial signals can stimulate stromal angiogenic activity primarily through changes in VEGF expression. 

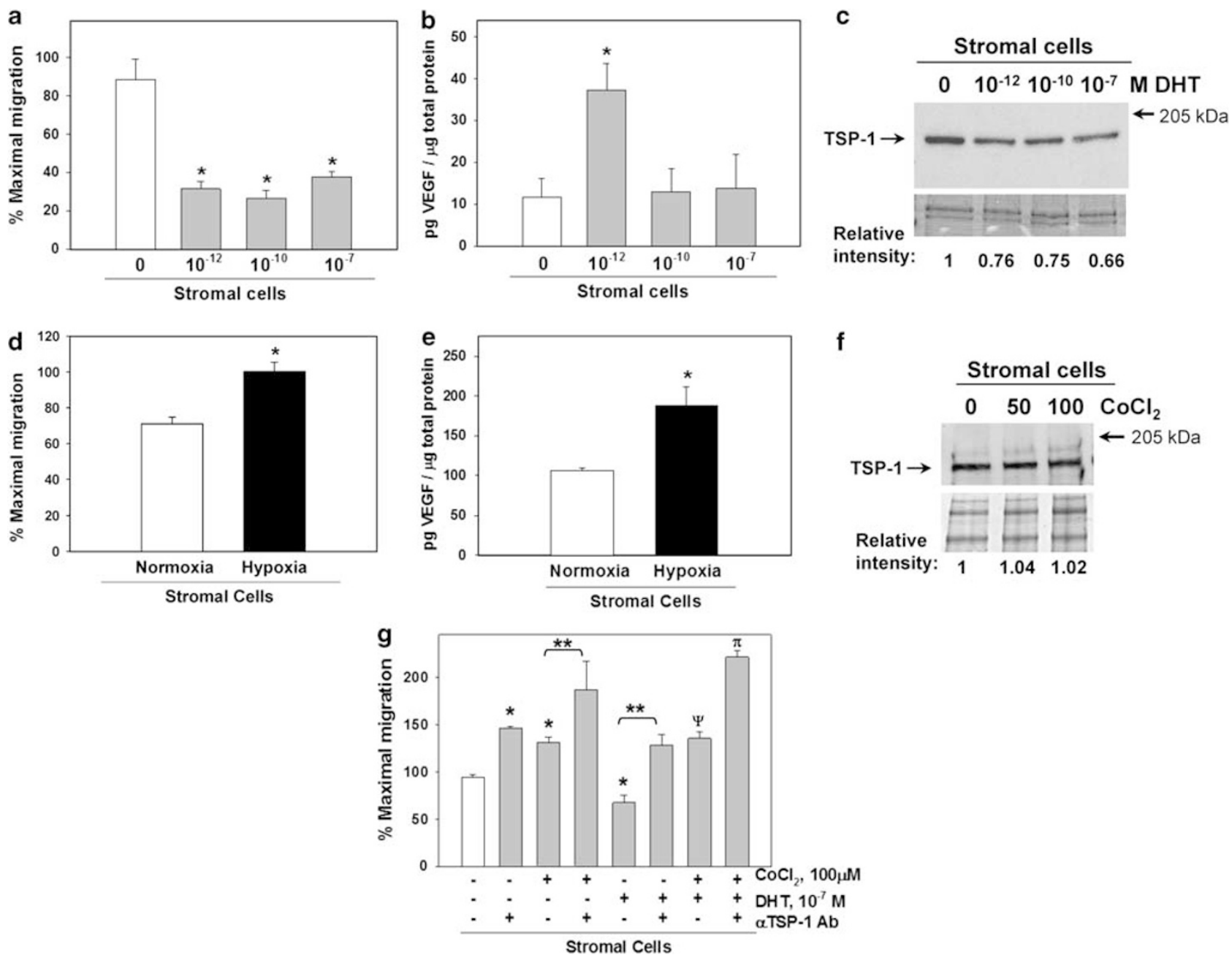

Figure 3 Androgens inhibit whereas hypoxia induces angiogenic activity in normal prostate stromal cells. Normal prostate stromal cells (PrSCs) were treated with DHT $\left(0-10^{-7} \mathrm{M}\right)$ or grown under standard conditions (normoxia) or hypoxia-treated conditions $(50-100 \mu \mathrm{M} \mathrm{CoCl} 2$ or grown in a hypoxia chamber, $0.5 \% \mathrm{O}_{2}$ (hypoxia)) and serum-free conditioned media collected. (a) Angiogenic activity was assessed in conditioned media ( $\left.20 \mu \mathrm{g} / \mathrm{ml}\right) \mathrm{using}$ a microvascular endothelial cell migration assay. Data are presented as the mean \pm s.e. of the percent maximum migration toward the positive control. (b) VEGF levels were assayed by ELISA. Data are presented as mean \pm s.d. of two replicates. (c) TSP-1 expression was evaluated by western blot analysis. The lower panel is an identically loaded Coomassie-stained gel to show equal protein loading between lanes. Relative intensity was determined by densitometry. Protein size standard is indicated. Angiogenic activity (d) and VEGF levels (e) were measured as above in hypoxia-treated cells. (f) TSP-1 expression was evaluated as above. (g) The functional activity of TSP-1 in media conditioned by PrSCs treated with $\mathrm{DHT}\left(10^{-7} \mathrm{M}\right)$ and/or CoCl $2(100 \mu \mathrm{M})$ was tested by the addition of neutralizing anti-TSP-1 antibody in a migration assay. Data are presented as the mean \pm s.e. of the percent maximal migration toward the positive control. ${ }^{*}$ Significantly different compared to untreated controls in each experiment, $P<0.05$. ${ }^{*}$ Samples between bars are significantly different, $P<0.05$. ${ }^{\psi}$ Significantly increased compared to untreated or DHT treated, $P<0.002$, but not significantly different than $C_{0} C_{2}$ alone, $P=0.64$. ${ }^{\pi}$ Significantly increased over the combined hypoxia and DHT treatment sample, $P<0.00001$.

\section{TSP-1 Expression Increases in Response to Androgen Ablation in Vivo}

Because DHT and hypoxia modify PrEC and PrSC angiogenic activity and TSP-1 expression in vitro in opposing directions, we asked if androgens suppressed TSP-1 expression in vivo using a mouse castration model and human PCa tissues. We observed localization of TSP-1 in both the stromal and epithelial compartments of the ventral, lateral and dorsal lobes of the intact mouse prostate (Figure 5a). Although epithelial expression was variable between glands, it was upregulated in the dorsal prostate lobe by 3 days after castration (Figure 5a).
These observations are consistent with a study in rats showing an increase in TSP-1 expression in post-castration tissues. ${ }^{21}$ We graded the TSP-1 staining in the epithelium and stroma, showing a significant increase in staining in both compartments after castration (Figure $5 \mathrm{~b} ; n=5$ per group; $P<0.008)$. As expected, MVD was reduced in the castrated tissues $(3.4 \pm 0.43$ vs $1.92 \pm 0.39 ; P<0.003)$. To determine if MVD correlated with TSP-1 staining, we calculated an MVD/ TSP-1 staining ratio, and this ratio was significantly decreased in the castrated mice (Figure $5 c ; P<0.012$ ). We have previously shown that in human PCa specimens there is a 

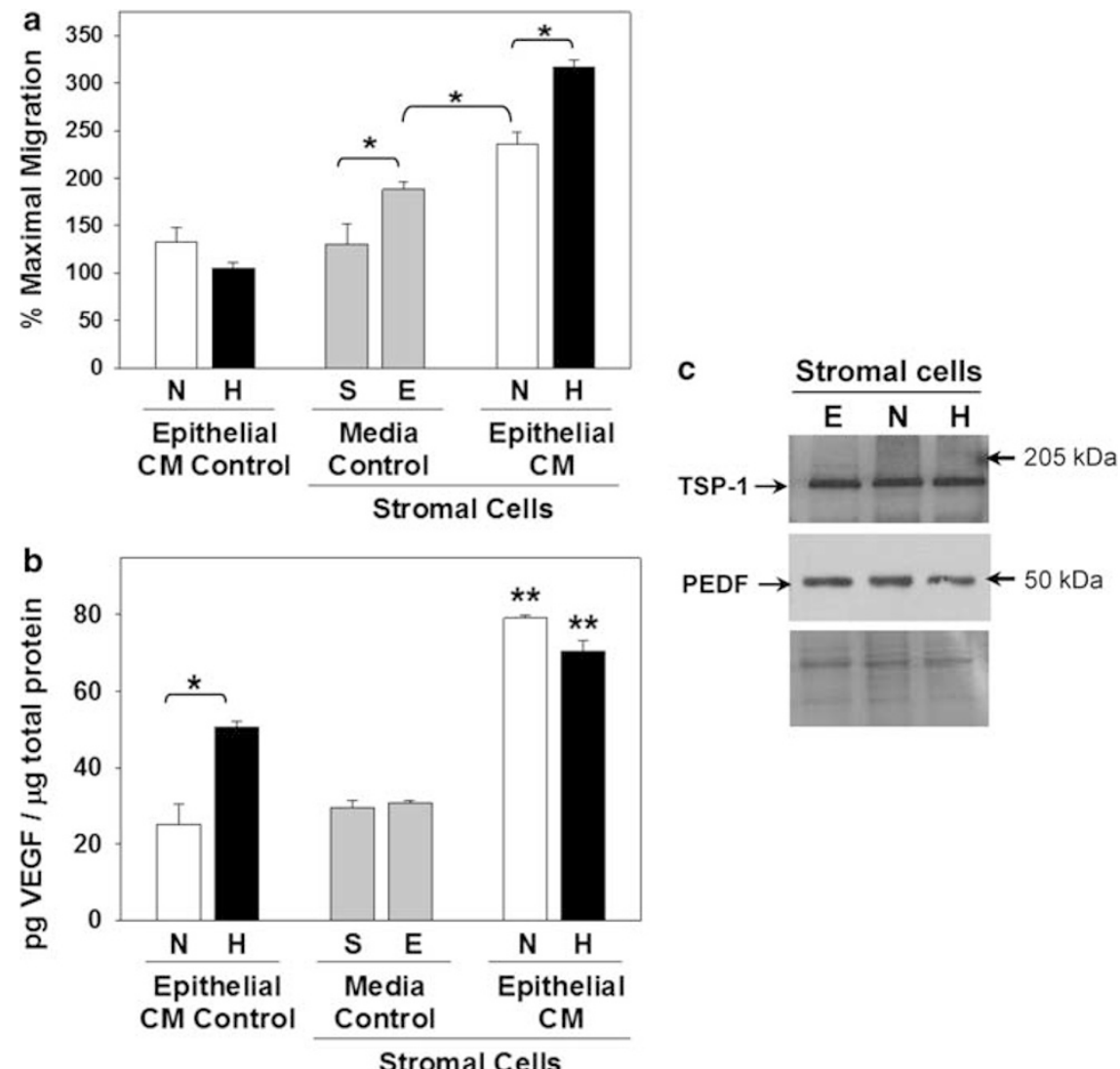

Stromal Cells

Figure 4 Stromal-epithelial interaction regulates net angiogenic response. Normal stromal cells were treated with normal epithelial cell conditioned media collected under standard (normoxia, $\mathrm{N})$ or hypoxic $\left(\mathrm{H}, 0.5 \% \mathrm{O}_{2}\right)$ conditions. As a control, stromal cells were grown in both epithelial media $(\mathrm{E})$ and their standard stromal media (S). (a) Angiogenic activity was tested using a microvascular endothelial cell migration assay. Data are presented mean \pm s.e. of the percent maximal migration toward the positive control. (b) VEGF levels were measured by ELISA, and data are presented as mean \pm s.d. (c) TSP-1 and PEDF expression were evaluated by western blot analysis. The lower panel is an identically loaded gel to show equal protein loading between lanes. Protein levels relative to cells grown in epithelial media (E) were determined by densitometry but showed no significant changes. Protein size standards are indicated. ${ }^{*}$ Samples between bars are significantly different from each other, $P<0.05$. ${ }^{*}$ Significantly increased over stromal cells grown in epithelial media, $P<0.006$.

positive correlation between MVD/TSP-1 ratio and higher grade cancers, ${ }^{5}$ and other studies have shown that stromal MVD decreases after ADT in human cancer tissues. ${ }^{34,35}$ In addition, one study has reported that patients undergoing ADT have increased TSP-1 levels compared to patients who had not undergone ADT. ${ }^{4}$ However, a direct correlation between androgen-withdrawal and TSP-1 expression was not possible in this study. Therefore, we addressed this question by examining TSP- 1 expression in patient-matched PCa biopsy specimens taken before and 3-7 days after androgenablation therapy. In pre-therapy specimens, TSP-1 was minimal to absent in both the stromal and epithelial cell compartments (Figure 5d). In two of eight cases, the posttherapy TSP- 1 staining remained unchanged compared to the pre-therapy, with only focal epithelial staining present in these specimens. However, in the other six cases, there was a marked increase in TSP-1 staining in the epithelial cells with some focal stromal positivity noted after therapy (Figure 5d). When quantified, the TSP-1 staining was significantly increased in the epithelial compartment $(P<0.013)$ whereas the stromal staining was not increased (Figure 5e). Taken together, these observations suggest that TSP-1 functions in the vascular regression induced by androgen withdrawal. As we have similar results with PEDF expression (increase in seven of eight of patient tissues ${ }^{6}$ ), it seems that angiogenesis inhibitors have a critical role in mediating ADT-induced cancer regression.

\section{Loss of TSP-1 Expression in the Mouse Results in Prostate Hyperplasia}

We and others have previously reported that loss of TSP-1 disrupts the normal architecture of several tissues, including the lungs, pancreas, liver and testes; ${ }^{23,32}$ however, the prostate phenotype has not been reported. The prostate in TSP-1 KO was compared to age-matched $\mathrm{C} 57 \mathrm{Bl} / 6$ wild-type mice, the background strain of the TSP-1 KO with a minimum of five mice per group analyzed. In the TSP-1 KO, we observed dysregulated epithelial growth in the ventral, dorsal and lateral lobes of the prostate, as compared to controls (Figure 6). Hyperplasia was present in both the ventral 
a

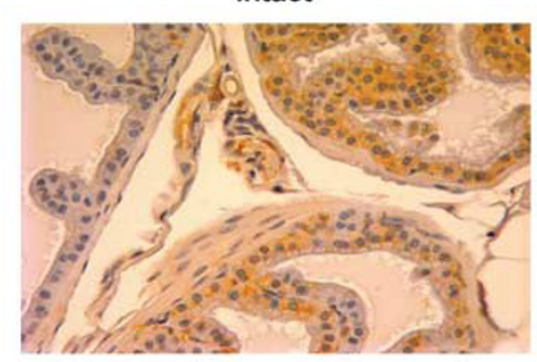

d
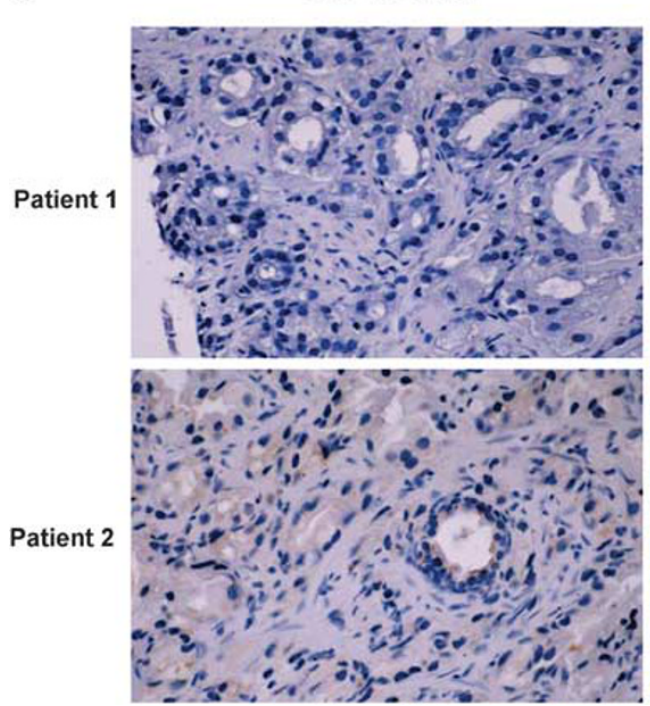

3 d post-castration

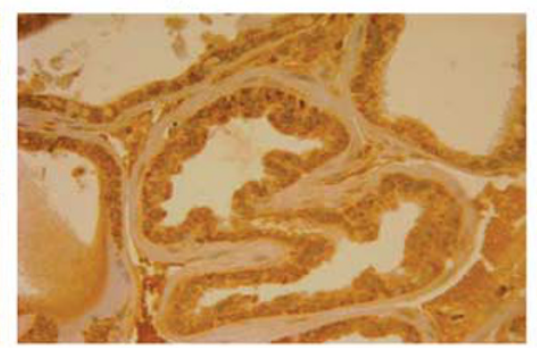

Post-therapy
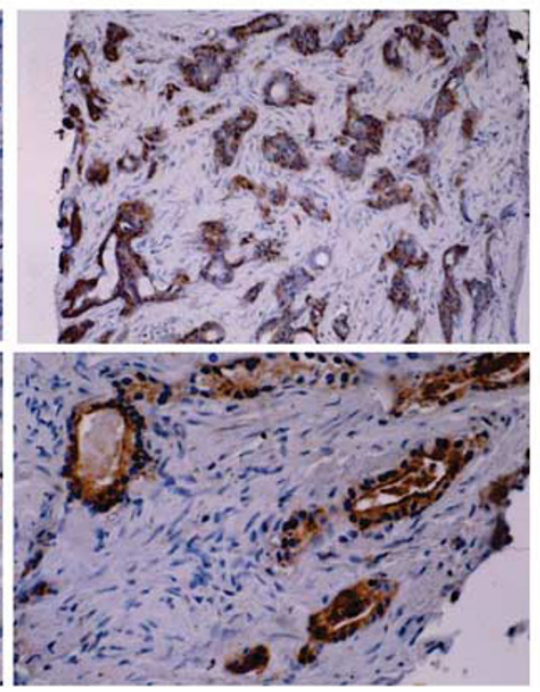

b

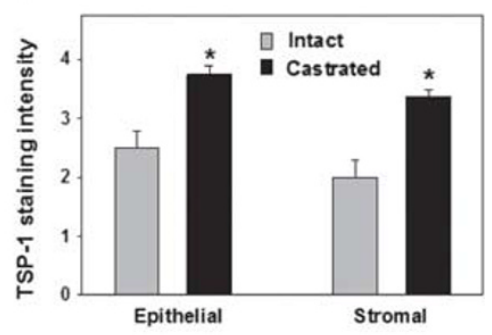

c
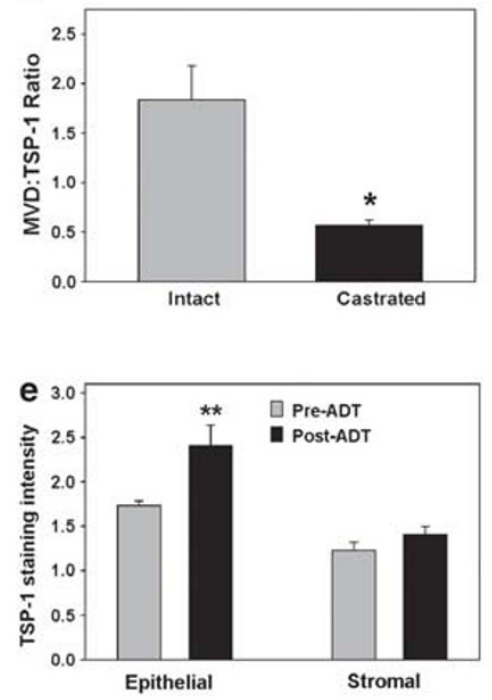

Figure 5 TSP-1 expression increases after androgen ablation in the mouse prostate and in patient-matched biopsy specimens in vivo. Prostate tissue sections were immunostained with anti-TSP antibody. (a) Prostate tissues were collected from intact or castrated (1-21 days after castration; $n=5$ per group) wild-type (C57BI/6) mice. Sections from intact and 3 days after castration are shown. (b) TSP-1 staining intensity was graded on a 1-4 scale in the epithelium and stroma of the dorsal prostate. (c) The vessels were counted in the dorsal prostate stroma and the MVD/TSP-1 staining ratio calculated. (d) Patient-matched biopsies were taken from PCa patients before and 3-7 days after androgen ablation therapy. Six of eight patient tissues showed increased immunoreactivity after androgen ablation therapy. Pre- and post-therapy tissues are shown for two patients. (e) TSP-1 staining was graded on a 1-4 scale in the epithelial and stromal compartments. ${ }^{*}$ Significantly increased in castrated compared to intact, $P<0.012$, and ${ }^{\star *}$ significantly increased in human post-ADT tissues, $P<00.013$.

and dorsal lobes and was evident by 3 months of age and progressive with age. The hyperplasia was characterized by increased tufting, stratification of cells in the epithelial cell layer with non-basally located, hyperchromatic and pleomorphic nuclei. In the lateral prostate, there was also a metaplasia phenotype evident by regions of cells with mucin accumulation, which does not normally occur in the lateral prostate. The epithelial hyperplasia was characterized by immunostaining prostate tissues with antibody against PCNA and factor VIII-related antigen for proliferation and MVD, respectively (Figure $7 \mathrm{a}$ and $\mathrm{b} ; n=6$ per group). TSP-1 KO mice showed a twofold increase in percent PCNA-positive epithelial nuclei when compared to wild-type mice $(P<0.007$; Figure 7c), and stromal MVD was increased twofold in the TSP-1 KO prostate tissues as compared to wild-type controls $(P<0.0003$; Figure $7 \mathrm{~d})$. These data show that TSP-1 function is necessary for in vivo regulation of prostate growth, and the increase in stromal MVD supports angiogenic regulation as one mechanism of this growth regulation.

\section{TSP-1 Activates TGF- $\beta$ in the Mouse Prostate}

TSP-1 is a multifunctional protein, and in addition to its antiangiogenic activity, TSP-1 can also activate latent TGF- $\beta$ in vivo in other tissue types, ${ }^{23}$ but prostate activation has not been investigated. As TGF- $\beta$ is a key regulator of prostate growth, we examined prostate tissues from wild-type and TSP-1 KO mice by immunostaining, using antibodies against total and active TGF- $\beta$. With the antibody against total TGF- $\beta$, there was no difference in immunoreactivity between wild-type and TSP-1 KO tissues (Figure $8 \mathrm{a}$ and b; $n=5$ per group). With antibody against active TGF- $\beta$, staining was similar between wild-type and TSP-1 KO in the lateral and ventral lobes of the prostate. However, in the TSP-1 $\mathrm{KO}$ dorsal prostate, there was significantly less active TGF- $\beta$ compared to wild-type tissues (Figure $8 \mathrm{c}$ and $\mathrm{d}$ ). 
WT
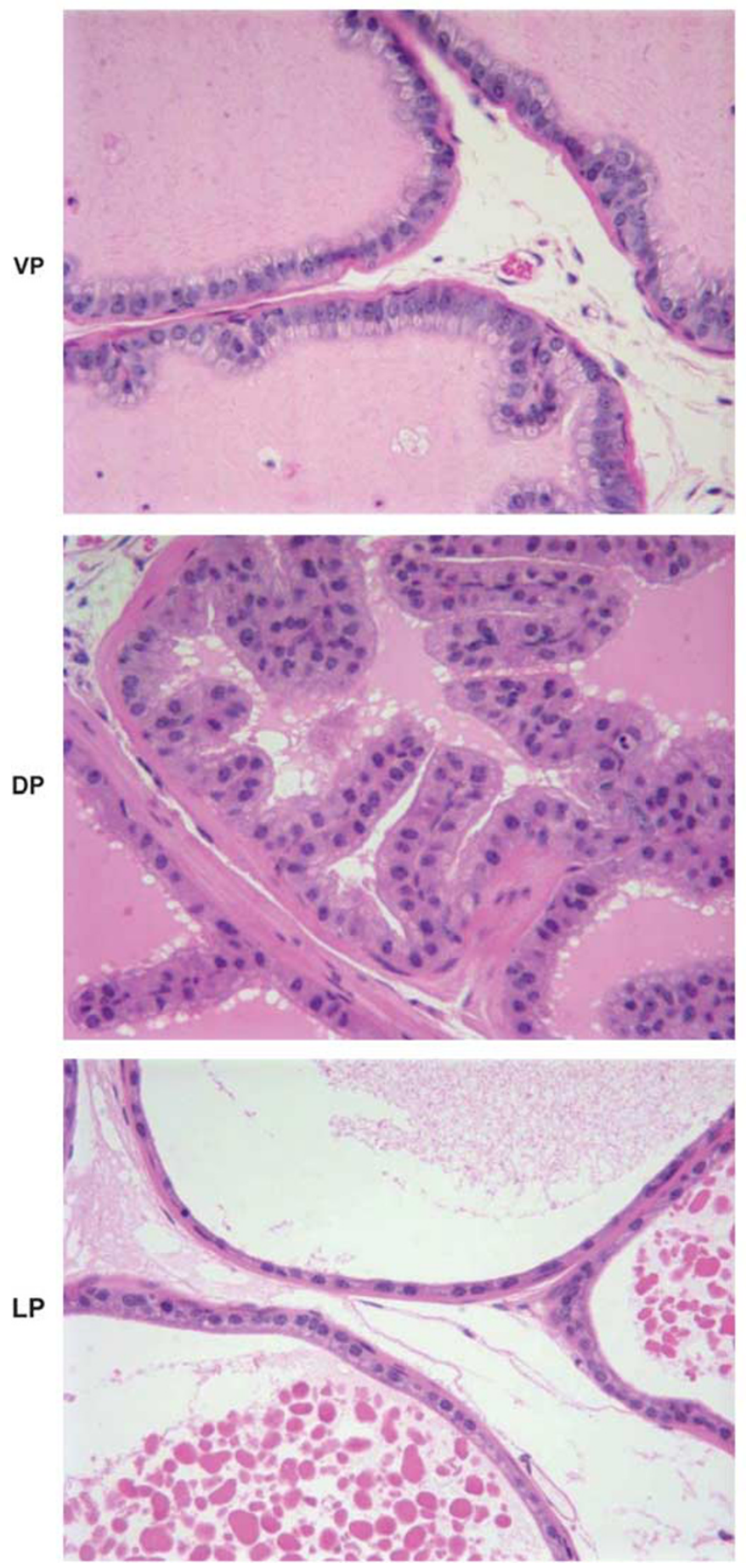

TSP KO
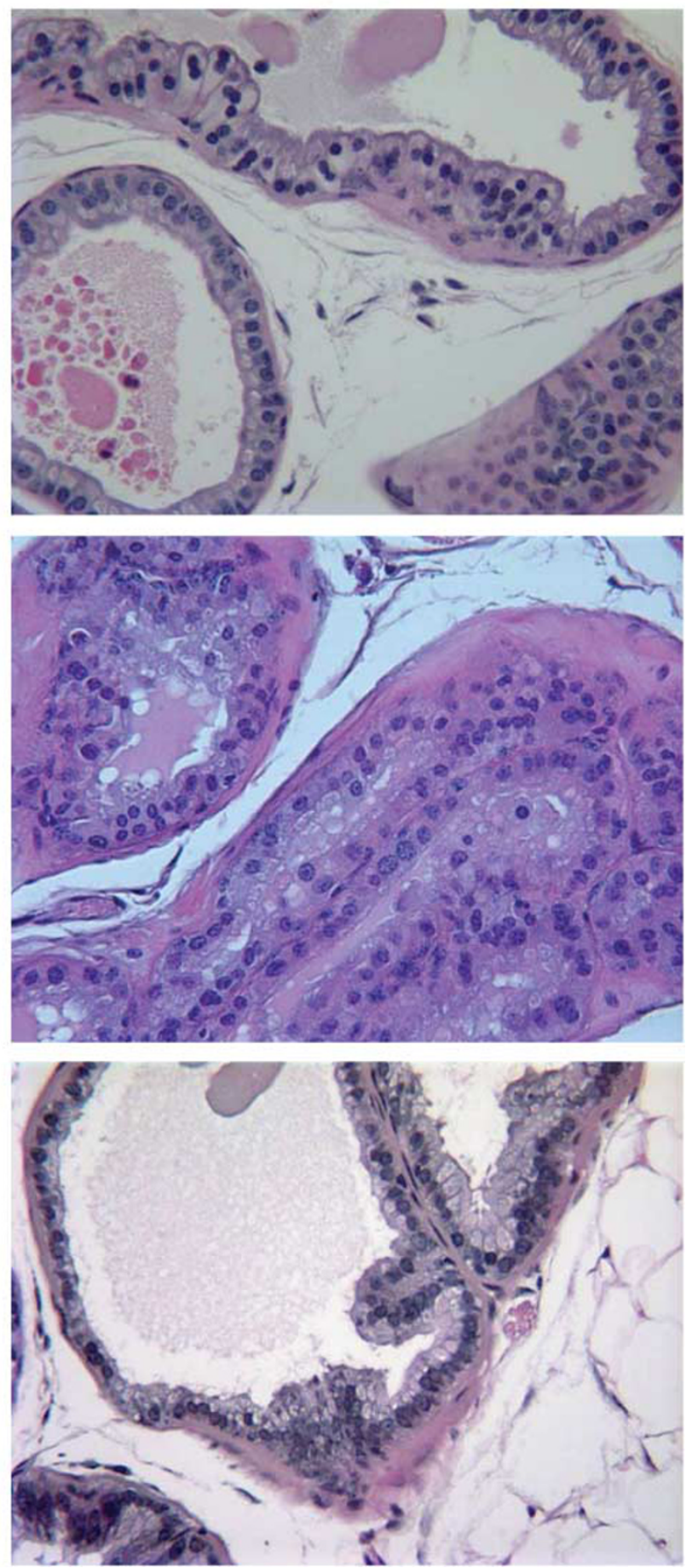

Figure 6 The TSP-1 KO mouse has prostate hyperplasia. Compared to wild-type (WT) mouse, the TSP-1 KO (TSP KO) mouse prostate showed epithelial and stromal cell hyperplasia by 3 months of age with nuclear atypia (hyperchromatic and pleomorphic nuclei) in the glandular cells. Evidence of hyperplasia was observed in the ventral prostate (VP), dorsal prostate (DP) and lateral prostate (LP). Representative H\&E sections are shown at 5-6 months of age.

When this staining was quantified by grading staining intensity within the glands on a 1-3 scale, there was significantly fewer high-staining glands (grade 3 ) in the TSP-1 KO prostate as compared to the wild-type tissues $(P<0.001$; Figure 8e). These data identify a novel function for TSP-1 in the prostate and suggest that TSP- 1 activation of TGF- $\beta$ is lobe specific. This difference may have significance as the dorsal lobe is considered to be the most analogous to the human prostate peripheral zone where the majority of $\mathrm{PCa}$ arises. 
a

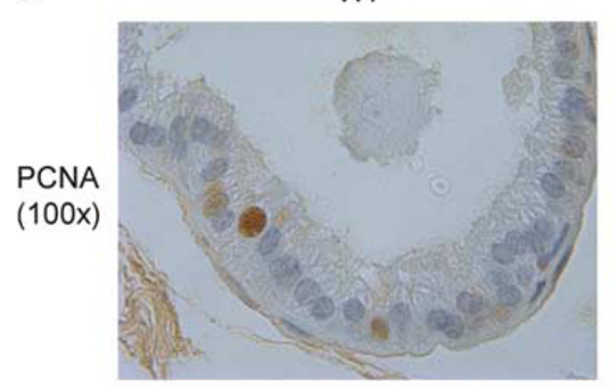

b

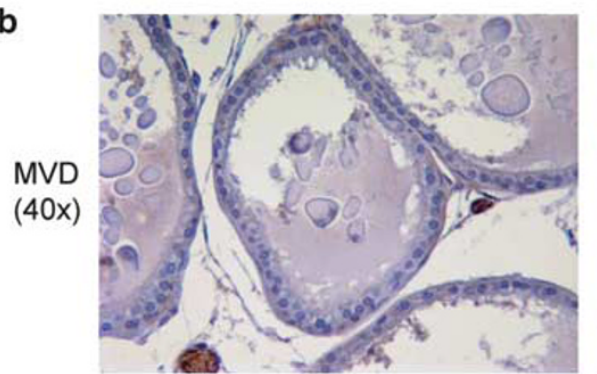

TSP KO
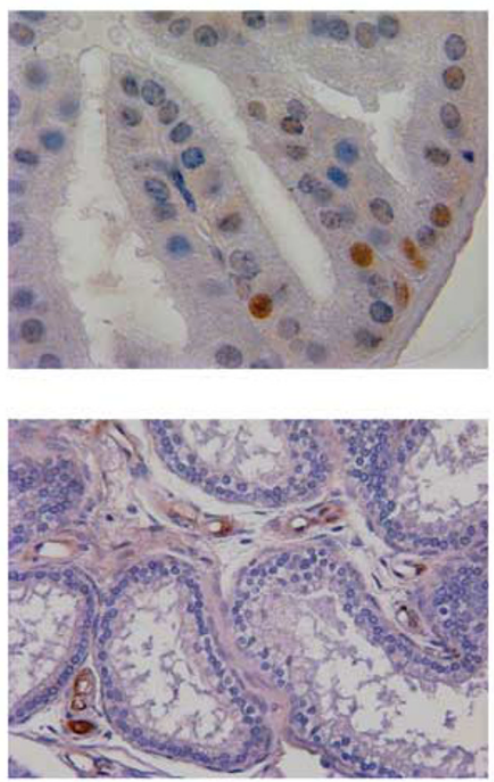

C.
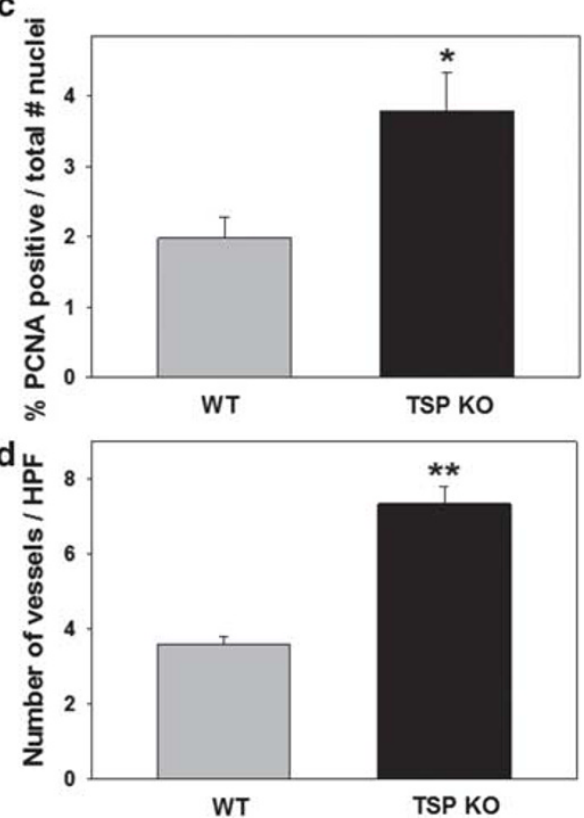

Figure 7 Prostate tissue of TSP-1 KO has increased epithelial cell proliferation and MVD. Mouse prostate tissues were immunostained with anti-PCNA (a) and anti-factor VIII-related antigen (b) to assess proliferation and MVD, respectively. Representative tissue sections are shown. (c) The number of PCNA-positive and the total number of epithelial nuclei were counted at $\times 100$ to quantify proliferative activity. A minimum of 150 nuclei were counted for each mouse ( $n=6$ per group). PCNA positivity is presented as a percent of the total number of nuclei counted; ${ }^{\star} P<0.007$. (d) MVD quantified by counting vessels in five high-power fields $(\mathrm{HPF} ; \times 40)$ for each mouse $\left(n=6\right.$ per group; $\left.{ }^{\star *} P<0.00003\right)$.

From studies in other tissue types, it also appears that active TGF- $\beta$ can induce TSP-1 expression, showing a positive feedback regulation. To investigate this in prostate cells, we treated PrSCs with neutralizing TGF- $\beta$ antibodies. TSP-1 secretion in treated cells was suppressed $25 \%$ compared to untreated cells (Figure 8f). In addition, above we show that treatment with $10^{-7} \mathrm{M}$ DHT did not induce VEGF expression (Figure $3 \mathrm{~b}$ ); however, when neutralizing TGF- $\beta$ antibody was added, VEGF was significantly increased (Figure $8 \mathrm{~g}$ ). Although TGF- $\beta$ can act directly on endothelial cells, these data suggest that in the prostate it also contributes to angiogenic regulation through inducing TSP-1 expression and suppressing VEGF expression.

To determine if TSP- 1 activates TGF- $\beta$ in vivo after androgen withdrawal, we castrated wild-type and TSP-1 KO mice, collected prostate tissues at 1-21 days after castration and immunostained for total and active TGF- $\beta$. In the castrated tissues, with antibody against total TGF- $\beta$, no differences were observed between wild-type and TSP-1 KO mice. In the wild-type mice, there was a characteristic thickening of the stroma by 3 days after castration compared to the intact animals, and active TGF- $\beta$ strongly localized to this region (Figure 9a and b). Although some of this staining is nonspecific staining of the red blood cells leaking from the regressing vasculature, stromal positivity is also evident (Figure 9b). In contrast, TSP-1 KO mice did not show a thickening of the stroma and active TGF- $\beta$ levels were unchanged in post-castration tissues (Figure $9 \mathrm{c}$ and $\mathrm{d}$ ). These observations suggest that TSP-1 expression is necessary for the stromal response by increasing TGF- $\beta$ activation in postcastration tissues.

\section{DISCUSSION}

The importance of angiogenesis in tumor growth is well established, and a growing body of data supports its importance in regulating normal organ homeostasis as well. Prostate development and maintenance of the adult gland is dependent on androgens, and this appears to be mediated in part by regulation of angiogenesis. Androgen withdrawal induces regression of the glandular epithelium; however, endothelial apoptosis and vascular regression precedes the epithelial apoptosis. ${ }^{18-20}$ While the role of the angiogenesis inducer, VEGF, is well studied in this process, the role of angiogenesis inhibitors has not been well established. Although the initial vascular regression can be explained by a sharp decrease in VEGF expression, ${ }^{14}$ the vascular regression leads to tissue hypoxia and VEGF returns to baseline levels. ${ }^{18-20}$ As the vascular regression continues, other angiogenic mediators must be involved. Here we show that TSP-1 expression increases after androgen withdrawal in normal mouse prostate tissues and in human PCa tissues. Thus, the antiangiogenic activity of TSP-1 would contribute to the continued vascular regression. Similarly, we have observed upregulation of PEDF in response to androgen withdrawal in normal mouse prostate and human PCa tissues. ${ }^{6}$ These observations suggest that angiogenesis inhibitors are critical 

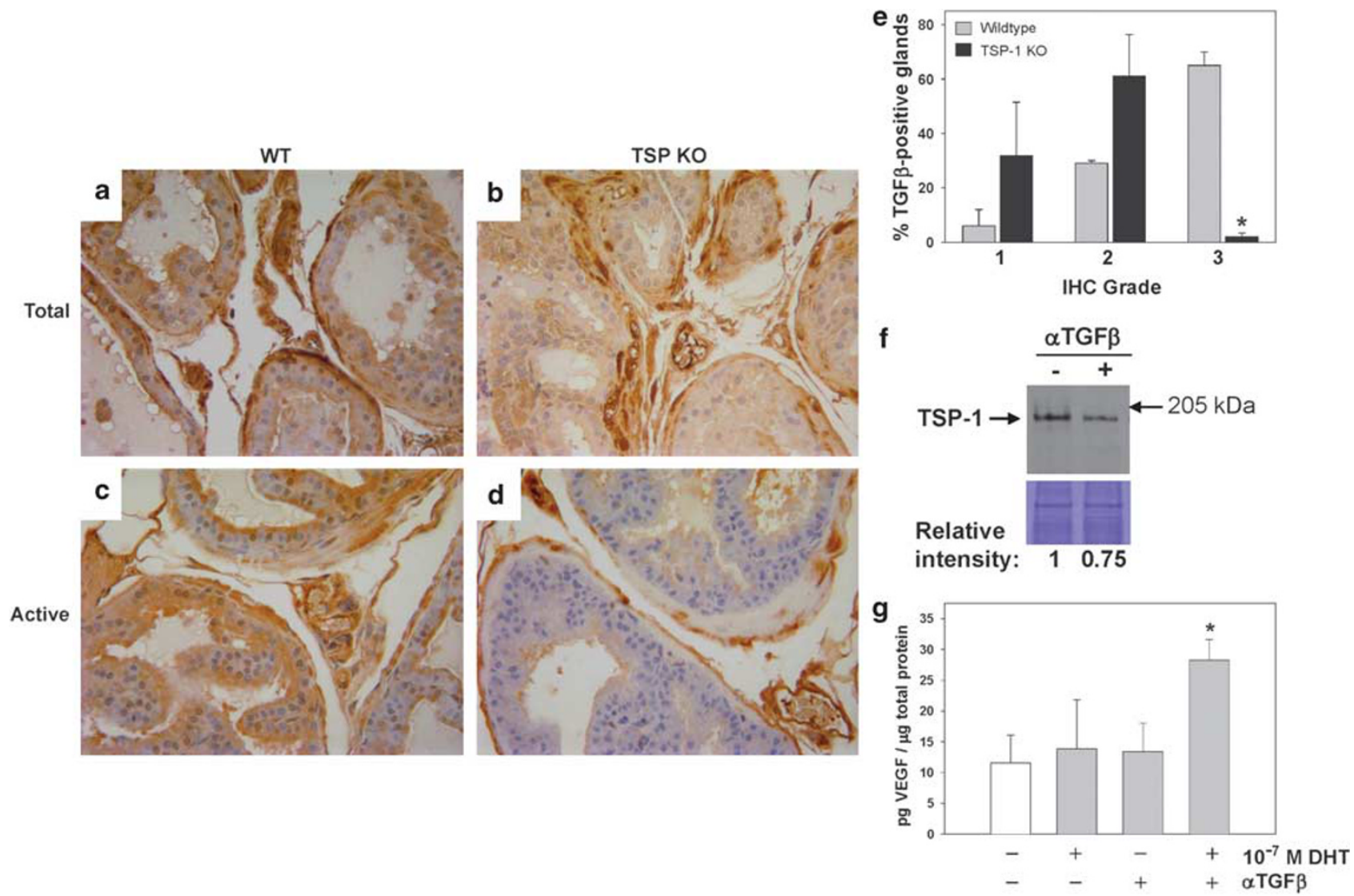

Figure 8 TSP-1/TGF- $\beta$ regulation in the prostate. Wild-type (C57BI/6) and TSP-1 KO mouse prostate tissues ( $n=5$ per group) were immunostained with antibody against total (a and $\mathbf{b})$ and active TGF- $\beta$ (c and $\mathbf{d}$ ). (e) In the dorsal prostate, where staining differences were observed, active TGF- $\beta$-positive glands were graded on a 1-3 scale: $1=$ light, $2=$ medium and $3=$ intense staining. The number of grade 3 glands was significantly decreased in the TSP-1 null mice as compared to wild type $\left({ }^{*} P<0.0001\right)$. (f) Stromal cells were treated with neutralizing TGF- $\beta$ antibody and TSP-1 levels assessed by western blot analysis. The lower panel is an identically loaded Coomassie-stained gel to verify equal protein loading. Protein levels relative to the untreated cells were quantified by densitometry. (g) VEGF levels in normal stromal cells treated with DHT \pm neutralizing TGF- $\beta$ antibody VEGF were measured by ELISA. ${ }^{*}$ Significantly decreased compared to untreated cells, $P<0.05$.

to androgen-mediated regulation of the stromal vasculature. These data are of particular interest because ADT is a primary therapy for metastatic disease and is used in conjunction with other therapies in locally advanced PCa. Supporting this, ADT has been shown to decrease stromal MVD in human PCa tissues. ${ }^{34,35}$ The reexpression of TSP-1 shown above, and our previous study showing reexpression of PEDF, ${ }^{6}$ both most strongly in the epithelial cells, suggests a critical role for these angiogenesis inhibitors in mediating ADT-induced PCa regression and that analysis of their expression after ADT could provide prognostic information.

As the prostate endothelial cells do not express the androgen receptor, ${ }^{15,16}$ it is likely that the epithelial and stromal cells mediate this response. To dissect this, we tested the androgen- and hypoxia-mediated angiogenic response in both cell types. Surprisingly, they revealed opposing responses in vitro. In epithelial cells, TSP-1 expression was suppressed by hypoxia, whereas in stromal cells hypoxia had no effect. With DHT treatment, however, stromal TSP-1 was suppressed whereas epithelial cell TSP-1 was not affected. Though other molecules likely contribute, the net angiogenic activity in response to either stimulus could be explained when VEGF, TSP-1 and PEDF levels were considered. With these opposing responses, it seemed likely that the in vivo response may be modified by cell interactions. Toward this, we showed that stromal cell angiogenic activity is stimulated by epithelial cell secretions and that this modulation was sensitive to changes in epithelial growth in normoxia $v s$ hypoxia. Although these data show a complex regulation of angiogenic mediators by stromal-epithelial interactions, they also show two caveats in angiogenic research. The first is that testing isolated epithelial cancer cells may not be representative of in vivo angiogenic activity, and the second is that measuring a single angiogenic mediator may not be an accurate indicator of angiogenic balance in the tissue.

Further supporting the critical role of angiogenesis and the inhibitor TSP-1 in regulating prostate growth, we also show that developmental loss of TSP-1 leads to prostate epithelial hyperplasia in mice, characterized by both increased epithelial cell proliferation and increased stromal angiogenesis. This phenotype was similar to the phenotype we observed in PEDF KO mice. Both molecules regulate prostate growth 

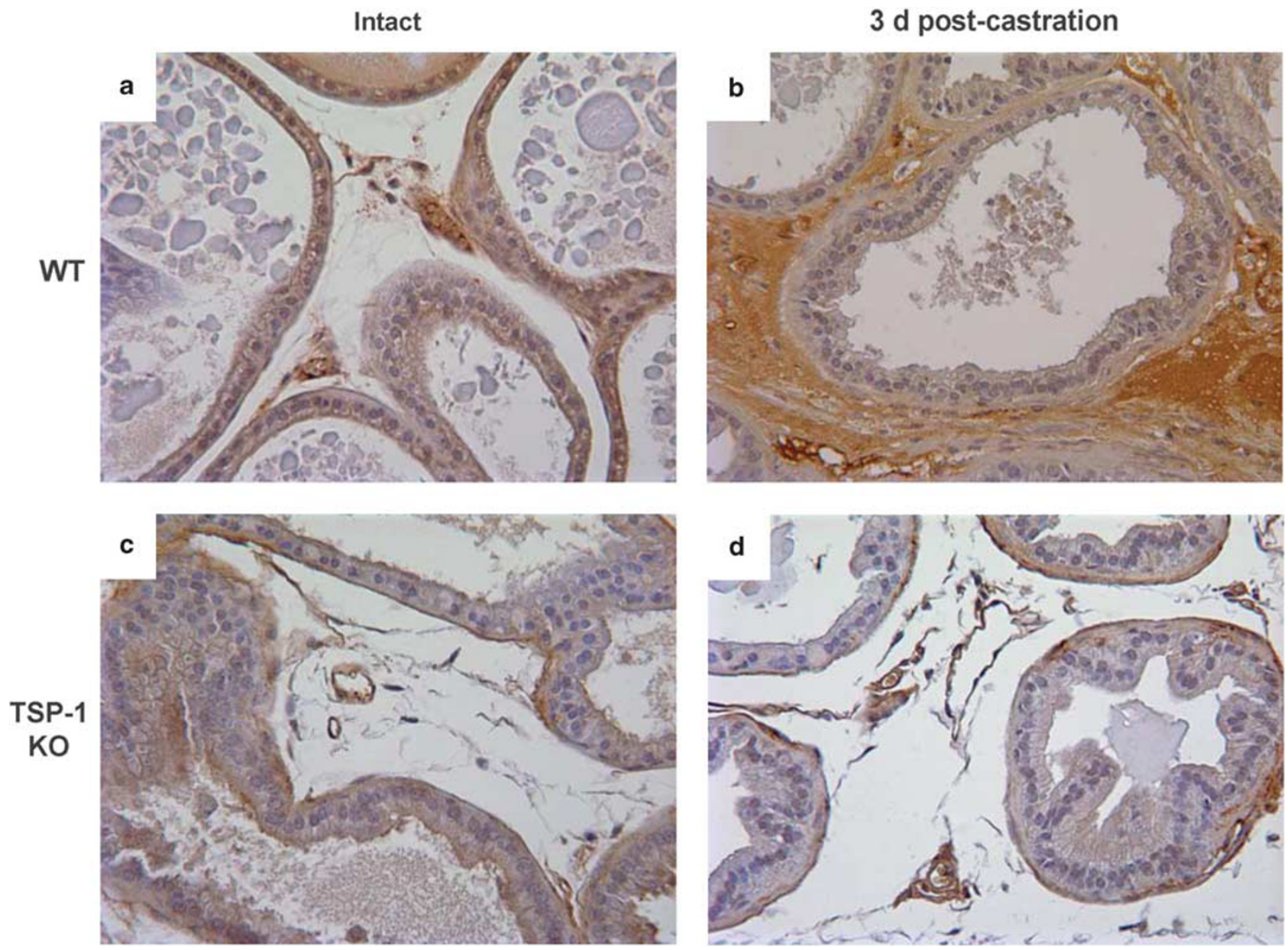

Figure 9 Stromal activation of TGF- $\beta$ is decreased in the TSP-1 KO prostate after castration. Wild-type (WT) and TSP-1 KO mice were castrated or sham-operated (intact), and prostate tissues were collected at 3-8 days after castration and immunostained with antibody against active TGF- $\beta$. TSP-1 KO did not have the stromal thickening seen in WT mice and active TGF- $\beta$ positivity was not increased in TSP- 1 KO ( $n=3$ per genotype per group per time point).

through vascular inhibition, and PEDF can also induce apoptosis of PCa cell. ${ }^{6}$ We have previously shown that TSP-1 and PEDF expression are decreased in PCa tissues compared to benign tissues. ${ }^{5,6}$ And, others have shown that circulating TSP-1 levels are decreased in PCa serum as compared to patients with benign prostatic hyperplasia and that these levels differentiated benign $v s$ malignant disease. ${ }^{36}$ These observations suggest a broader function of angiogenic inhibitors as growth regulators in the prostate.

TSP-1 and TSP-1-derived peptides have also shown efficacy in directly inhibiting PCa cell proliferation in vitro ${ }^{37}$ and xenograft growth in vivo. ${ }^{38,39}$ However, one study has noted that, in a LNCaP xenograft model, the tumors eventually escaped the inhibitory effects of TSP- $1,{ }^{21}$ which could be linked to progression to hormone-independent cancer. In this study, we show that TSP- 1 activated latent TGF- $\beta$ in the mouse prostate. TGF- $\beta$ is a negative regulator of normal PrECs. In human PCa, early stage cancers are sensitive to the growth inhibitory effects of TGF- $\beta$; however, advanced stage cancers are insensitive due to mutated or decreased expres- sion of TGF- $\beta$ receptors and altered intracellular signaling pathways. Thus, decreased sensitivity to the growth inhibitory effects of TGF- $\beta$ may be one mechanism by which tumors become insensitive to TSP-1 inhibition. Therefore, if TSP-1 expression is lost during tumorigenesis, multiple blockades to tumor growth are lost, including inhibition of stromal angiogenesis and activation of latent TGF- $\beta$. Thus, for PCa patients, combining ADT with an antiangiogenic therapy, such as a VEGF-neutralizing therapy or a TSP-1 therapy, and/or a therapy targeting the TGF- $\beta$ pathway, could delay time to recurrence to androgen-independent disease.

Supplementary Information accompanies the paper on the Laboratory Investigation website (http://www.laboratoryinvestigation.org)

\section{ACKNOWLEDGEMENTS}

This work was supported in parts by NIH Grants CA64329 and CA095301 (SEC) and DOD Grant DAMD17-99-1-9521 (JAD), and P50-CA090386 (CL) and by a NorthShore University HealthSystem Research Career

Development Award (JAD). We thank Dr Jack Lawler (Yale University, New Haven, CT) for providing the TSP-1 knockout mice and Dr Beth Plunkett 
(NorthShore University HealthSystem, Evanston, IL) for her helpful discussions and critical analysis of this article.

\section{DISCLOSURE/CONFLICT OF INTEREST}

The authors declare no conflict of interest.

1. Lissbrant IF, Stattin P, Damber JE, et al. Vascular density is a predictor of cancer-specific survival in prostatic carcinoma. Prostate 1997;33: 38-45.

2. Silberman MA, Partin AW, Veltri RW, et al. Tumor angiogenesis correlates with progression after radical prostatectomy but not with pathologic stage in Gleason sum 5-7 adenocarcinoma of the prostate. Cancer 1997;79:772-779.

3. Mehta R, Kyshtoobayeva A, Kurosaki T, et al. Independent association of angiogenesis index with outcome in prostate cancer. Clin Cancer Res 2001;7:81-88.

4. Kwak C, Jin RJ, Lee C, et al. Thrombospondin-1, vascular endothelial growth factor expression and their relationship with p53 status in prostate cancer and benign prostatic hyperplasia. BJU Int 2002;89: 303-309.

5. Doll JA, Reiher FK, Crawford SE, et al. Thrombospondin-1, vascular endothelial growth factor and fibroblast growth factor-2 are key functional regulators of angiogenesis in the prostate. Prostate 2001:49:293-305.

6. Doll JA, Stellmach VM, Bouck NP, et al. Pigment epithelium-derived factor regulates the vasculature and mass of the prostate and pancreas. Nat Med 2003;9:774-780.

7. Franck-Lissbrant I, Haggstrom S, Damber JE, et al. Testosterone stimulates angiogenesis and vascular regrowth in the ventral prostate in castrated adult rats. Endocrinology 1998;139:451-456.

8. Lekas $E$, Johansson $M$, Widmark $A$, et al. Decrement of blood flow precedes the involution of the ventral prostate in the rat after castration. Urol Res 1997;25:309-314.

9. Lekas $E$, Engstrand $C$, Bergh A, et al. Transient ischemia induces apoptosis in the ventral prostate of the rat. Urol Res 1999;27:174-179.

10. Shabsigh A, Chang DT, Heitjan DF, et al. Rapid reduction in blood flow to the rat ventral prostate gland after castration: preliminary evidence that androgens influence prostate size by regulating blood flow to the prostate gland and prostatic endothelial cell survival. Prostate 1998;36:201-206.

11. Jain RK, Safabakhsh N, Sckell A, et al. Endothelial cell death, angiogenesis, and microvascular function after castration in an androgen-dependent tumor: role of vascular endothelial growth factor. Proc Natl Acad Sci USA 1998;95:10820-10825.

12. Joseph IB, Nelson JB, Denmeade SR, et al. Androgens regulate vascular endothelial growth factor content in normal and malignant prostatic tissue. Clin Cancer Res 1997;3:2507-2511.

13. Sordello S, Bertrand N, Plouet J. Vascular endothelial growth factor is up-regulated in vitro and in vivo by androgens. Biochem Biophys Res Commun 1998;251:287-290.

14. Shibata $Y$, Kashiwagi $B$, Arai S, et al. Direct regulation of prostate blood flow by vascular endothelial growth factor and its participation in the androgenic regulation of prostate blood flow in vivo. Endocrinology 2004;145:4507-4512.

15. Prins GS, Birch L. Immunocytochemical analysis of androgen receptor along the ducts of the separate rat prostate lobes after androgen withdrawal and replacement. Endocrinology 1993;132:169-178.

16. Prins GS, Birch L, Greene GL. Androgen receptor localization in different cell types of the adult rat prostate. Endocrinology 1991;129:3187-3199.

17. Levine AC, Liu XH, Greenberg PD, et al. Androgens induce the expression of vascular endothelial growth factor in human fetal prostatic fibroblasts. Endocrinology 1998;139:4672-4678.

18. Shabsigh A, Ghafar MA, de la Taille A, et al. Biomarker analysis demonstrates a hypoxic environment in the castrated rat ventral prostate gland. J Cell Biochem 2001;81:437-444.
19. Rudolfsson $\mathrm{SH}$, Bergh A. Testosterone-stimulated growth of the rat prostate may be driven by tissue hypoxia and hypoxia-inducible factor-1alpha. J Endocrinol 2008;196:11-19.

20. Rudolfsson $\mathrm{SH}$, Bergh A. Hypoxia drives prostate tumour progression and impairs the effectiveness of therapy, but can also promote cell death and serve as a therapeutic target. Expert Opin Ther Targets 2009;13:219-225.

21. Colombel $M$, Filleur $S$, Fournier $P$, et al. Androgens repress the expression of the angiogenesis inhibitor thrombospondin-1 in normal and neoplastic prostate. Cancer Res 2005;65:300-308.

22. Kazerounian S, Yee KO, Lawler J. Thrombospondins in cancer. Cell Mol Life Sci 2008;65:700-712.

23. Crawford SE, Stellmach V, Murphy-Ullrich JE, et al. Thrombospondin-1 is a major activator of TGF-beta1 in vivo. Cell 1998;93:1159-1170.

24. Schultz-Cherry S, Lawler J, Murphy-Ullrich JE. The type 1 repeats of thrombospondin 1 activate latent transforming growth factor-beta. J Biol Chem 1994;269:26783-26788.

25. Yehualaeshet T, O'Connor R, Green-Johnson J, et al. Activation of rat alveolar macrophage-derived latent transforming growth factor beta-1 by plasmin requires interaction with thrombospondin- 1 and its cell surface receptor, CD36. Am J Pathol 1999;155:841-851.

26. Jones $\mathrm{E}, \mathrm{Pu} \mathrm{H}$, Kyprianou N. Targeting TGF-beta in prostate cancer: therapeutic possibilities during tumor progression. Expert Opin Ther Targets 2009;13:227-234.

27. Wikstrom $P$, Westin $P$, Stattin $P$, et al. Early castration-induced upregulation of transforming growth factor beta1 and its receptors is associated with tumor cell apoptosis and a major decline in serum prostate-specific antigen in prostate cancer patients. Prostate 1999;38:268-277.

28. Danielpour D. Induction of transforming growth factor-beta autocrine activity by all-trans-retinoic acid and 1 alpha,25-dihydroxyvitamin D3 in NRP-152 rat prostatic epithelial cells. J Cell Physiol 1996;166: 231-239.

29. Goldberg MA, Dunning SP, Bunn HF. Regulation of the erythropoietin gene: evidence that the oxygen sensor is a heme protein. Science 1988;242:1412-1415.

30. Good DJ, Polverini PJ, Rastinejad F, et al. A tumor suppressordependent inhibitor of angiogenesis is immunologically and functionally indistinguishable from a fragment of thrombospondin. Proc Natl Acad Sci USA 1990;87:6624-6628.

31. Tolsma SS, Volpert OV, Good DJ, et al. Peptides derived from two separate domains of the matrix protein thrombospondin-1 have antiangiogenic activity. J Cell Biol 1993;122:497-511.

32. Lawler J, Sunday M, Thibert V, et al. Thrombospondin-1 is required for normal murine pulmonary homeostasis and its absence causes pneumonia. J Clin Invest 1998;101:982-992.

33. Berger AP, Kofler K, Bektic J, et al. Increased growth factor production in a human prostatic stromal cell culture model caused by hypoxia. Prostate 2003;57:57-65.

34. Matsushima H, Goto $\mathrm{T}$, Hosaka $\mathrm{Y}$, et al. Correlation between proliferation, apoptosis, and angiogenesis in prostate carcinoma and their relation to androgen ablation. Cancer 1999;85:1822-1827.

35. Montironi R, Diamanti L, Thompson D, et al. Analysis of the capillary architecture in the precursors of prostate cancer: recent findings and new concepts. Eur Urol 1996;30:191-200.

36. Shafer MW, Mangold L, Partin AW, et al. Antibody array profiling reveals serum TSP-1 as a marker to distinguish benign from malignant prostatic disease. Prostate 2007;67:255-267.

37. Bastian M, Steiner M, Schuff-Werner P. Expression of thrombospondin1 in prostate-derived cell lines. Int J Mol Med 2005;15:49-56.

38. Jin RJ, Kwak C, Lee SG, et al. The application of an anti-angiogenic gene (thrombospondin-1) in the treatment of human prostate cancer xenografts. Cancer Gene Ther 2000;7:1537-1542.

39. Quesada AJ, Nelius T, Yap R, et al. In vivo upregulation of CD95 and CD95L causes synergistic inhibition of angiogenesis by TSP1 peptide and metronomic doxorubicin treatment. Cell Death Differ 2005;12:649-658. 